National Zoological Park, the Astrophysical Observatory and the Division of Radiation and Organisms. The last-named refers to further work on the problems of photosynthesis and factors affecting plant growth both from a nutritional and radiation point of view. Many measurements have been made of the rate of carbon dioxide uptake and the intensity of fluorescence during the induction period of photosynthesis, and respiration and chlorophyll studies have been continued with a recording spectrographic carbon dioxide apparatus. A standardized technique has been worked out for the extraction of plant growth substances from the oat seedling. Publication of the final revised values of all solar constant results from all observing stations from 1923 to the present time is expected during the coming year. Archæological excavations in south-east Mexico have been continued in co-operation with the National Geographic Society. Excavations at the Lindenmeier site in northern Colorado have afforded much additional evidence of the presence of Folsom man.

Publications handled by the International Exchange Service, which serves as the official agency in the United States for exchange with foreign countries of documents and scientific publications, considerably decreased during the year, as the exchange of publications was suspended between the United States and all European countries except Great Britain, Finland and the Soviet Republic. A list of foreign depositories of Government documents is included in the report. The work of the Astrophysical Observatory concerning the radiation of the sun has been continued, and Dr. C. G. Abbot has endeavoured to evaluate the separate influences produced on weather by longrange solar periodicities, and changes in phase of the weather responses have been found to be due to seasonal influences.

\section{Recent Earthquakes recorded at Kew}

Durxng the week April 13-20, six large earthquakes were recorded at Kew Observatory. Three were on April 15, and there was one each on April 18, 19 and 20. The first on April 15 was very distant and the second was the important earthquake with epicentre near Colima (Mexico) (Nature, April 26, p. 507). This began recording with iP compressional on all three components at $19 \mathrm{~h}$. 22m. 19s. G.M.T. on April 15, and there followed a full suite of pulses, including $i S$ on all three components at $19 \mathrm{~h} .32 \mathrm{~m} .39 \mathrm{~s}$. G.M.T., $e L_{Q}$ on $N$ and $E$ at 19h. $46 \mathrm{~m}$. G.M.T., and $e L_{R}$ on the vertical and $E$ components at $19 \mathrm{~h} .50 \mathrm{~m}$. G.M.T. The earthquake finished recording at midnight on April 15, but what was probably the iP wave of an aftershock recorded on the vertical component seismograph at $19 \mathrm{~h} .58 \mathrm{~m}$. 25s. G.M.T. on April 15, superposed on the first. The maximum of the chief earthquake attained a ground amplitude of $880 \mu$ at Kew. The shock on April 18 only gave rise to small amplitudes. The one on April 19 recorded iP dilatational on the $Z$ component at 8h. 4m. 23s. G.M.T. and probably had its epicentre $7,220 \mathrm{~km}$. away. The earthquake on April 20 attained an amplitude of $69 \mu$ at Kew and was the second largest in the week. It began recording at $17 \mathrm{~h} .47 \mathrm{~m}$. $17 \mathrm{~s}$. G.M.T. with $i P$ on the $Z$ component probably from an epicentral distance of $5,440 \mathrm{~km}$., and finished recording at $18 \mathrm{~h} .40 \mathrm{~m}$.

\section{Earthquakes recorded in Switzerland}

THE Swiss Earthquake Bulletins from Zurich for November and December 1940 have just been received. Eight large earthquakes were recorded in November, and 10 in December. The earthquake of November 7, 1940 ,was recorded at all four observatories of Zurich. Chur, Basel and Neuchâtel and was felt with intensity IV at Gemeinde Muotatal, and at Schwyz with intensity III-IV. The earthquake of November 10 may have had its epicentre near Bucharest, and several aftershocks were also recorded. The shock of November 19 may have been near the Pacific Coast of northern Japan. On December 12 an earthquake, recorded at Chur, Zurich and Basel was felt with intensity IV in the region of the Mürtschenstock, Kt. Glarus, whilst the shock well recorded on December 22 at all four observatories, and in particular at Neuchâtel at 19h. 12m. 36.9s. G.M.T., probably had its epicentre in Central America.

\section{Announcements}

The title of reader in histology in the University of London has been conferred on Mr. Keith C. Richardson in respect of the post held by him at University College.

The Institute of Wireless Technology and the British Institution of Radio Engineers have fused, and in future the combined body will be known as "The British Institution of Radio Engineers Incorporated with the Institute of Wireless Technology". The president is Mr. S.A.Hurren, and Mr. G. D. Clifford has been appointed general secretary. The first annual general meeting of the combined body will be held in June, when the election of a council for 1941-42 will take place. All communications should be addressed to the Institution at Duke Street House, Duke Street, London, W.1.

A recent issue of the Evening Standard (London) quotes a British United Press message stating that traces of "a hitherto unknown prehistoric civilization have been found at Ipiutak on Point Hope, Alaska". It was already known that a very early and welldeveloped culture existed in Alaska, and the above message suggests new finds, confirmation of which will be awaited with interest.

There seems to be some misunderstanding concerning the leading article entitled "Relationship of Pure and Applied Biology" which was published in Nature of April 12, p. 427. As a leading article, the views expressed are, of course, those of the editors of NatuRe (formulated after considerable inquiry), and not those of a single individual. Neither is the article a summary of the discussion (to which reference is made) at a joint meeting of the Association of Applied Biologists and the Society for Experimental Biology. Summaries of discussions are published as such, and not as leading articles. 